\title{
O conceito de Heterocentrismo: um conjunto de crenças enviesadas e sua permanência
}

\author{
Jaqueline Gomes de Jesus - Universidade de Brasilia, Brasilia/DF, Brasil
}

\begin{abstract}
$\overline{\overline{R e s u m o}}$
Preconceitos podem ser expressos tanto por meio de ações discriminatórias quanto de discursos depreciativos. Este artigo objetiva identificar, com base em análise de diferentes teorias, a permanência na sociedade, por meio de práticas discursivas, políticas e mesmo terapêuticas, de um conjunto de crenças denominado "heterocentrismo", o qual é imbuído de uma carga simbólica negativa com relação à população homossexual, que conflita com mudanças nas relações interpessoais e grupais, ocasionadas pela insurgência dos novos movimentos sociais e da inclusão cada vez mais presente no cotidiano dos grupos sociais e organizações. Esboça-se um paradigma propenso ao reconhecimento não-estereotipado dos grupos discriminados, em especial os identificados pela dimensão da orientação sexual.

Palavras-chave: Preconceito; Discriminação; Orientação sexual; Gênero; Heterocentrismo.
\end{abstract}

The Concept of Heterocentrism: A Set of Biased Beliefs and its Permanence

\begin{abstract}
Prejudices can be expressed both through discriminatory actions and derogatory discourses. This article aims to identify, from the analysis of different theories, the permanence in society, through discursive, political and even therapeutic practices, of a set of beliefs named "heterocentrism", which is imbued with a negative symbolic load with respect to the homosexual population, which conflicts with changes in interpersonal and group relations, caused by the insurgency of new social movements and the inclusion more present in the everyday life of the social groups and organizations. A paradigm is outlined leaning to the non-stereotyped recognition of the discriminated groups, especially those identified by the dimension of the sexual orientation.

Keywords: Prejudice; Discrimination; Sexual orientation; Gender; Heterocentrism.
\end{abstract}

\section{El Concepto de Heterocentrismo: Un Conjunto de Creencias Sesgadas y su Permanencia}

\section{Resumen}

Perjuicios se pueden expresar a través de acciones discriminatorias como de discursos despectivos. Este artículo tiene como objetivo identificar, a partir del análisis de distintas teorías, la permanencia en la sociedad, por medio de prácticas discursivas, políticas e incluso terapéuticas, de un conjunto de creencias llamado "heterocentrismo", que está impregnado de un simbólico negativo con respecto a la población homosexual, que entra en conflicto con los cambios en las relaciones interpersonales y de grupo, causadas por la insurgencia de los nuevos movimientos sociales y de la inclusión cada vez más presente en la vida cotidiana de los grupos sociales y organizaciones. Se esboza un paradigma propenso al reconocimiento no estereotipado de grupos discriminados, especialmente los señalados por la dimensión de la orientación sexual.

Palabras clave: Perjuicio; Discriminación; Orientación sexual; Género; Heterocentricismo.

Os fundamentos perpetuadores da exclusão, como demonstra Sawaia (2002), encontram-se no tecido social, cuja organização historicamente construída reforça concepções e comportamentos machistas, racistas, elitistas, homofóbicos ${ }^{1}$, entre outros, quando não recrimina, pune ou deprecia atitudes agressivas contra grupos sociais discriminados. Nesse sentido, apontam Stoer, Magalhães e Rodrigues (2004), a relação exclusão/inclusão deve ser problematizada a partir dos seus contextos locais, nacionais e supranacionais.

As minorias sociais têm ocupado cada vez mais espaço no âmbito das transformações nas relações interpessoais, grupais, de massa e globais na sociedade informacional (Castells, 1996), devido à interação entre a estrutura social e as novas tecnologias da comunicação que permitem a troca eficaz e rápida de informações entre diferentes culturas, grupos ou pessoas com objetivos em comum. A reflexão sobre os direitos desses grupos ultrapassa as barreiras jurídicas e envolve as epistemologias e práticas que estruturam a ciência psicológica, em seus diversos âmbitos de atuação.

\footnotetext{
${ }^{1}$ A homofobia se caracteriza por ações discriminatórias contra homossexuais (Borrillo, 2010).

Disponivel em wnw.scielo.br
}

A dificuldade para o reconhecimento efetivo dos direitos de um segmento da população costuma se relacionar a preconceitos, mitos ou estereótipos culturalmente estabelecidos, mas cuja naturalização tem sido cada vez mais criticada na atualidade (Pérez-Nebra \& Jesus, 2011).

De acordo com Lizuka e Brincas (1999), a iniciativa privada tem assumido, cada vez mais, o protagonismo quanto ao serviço voluntário e se envolvido cada vez mais com realizações que minoram as discrepâncias sociais, em consonância com a intensificação de ações governamentais no sentido de implementar a Convenção 111 da Organização Internacional do Trabalho (1996) que define como discriminação qualquer forma de exclusão que altere a igualdade de oportunidades.

No Brasil contemporâneo, além dos debates sobre a necessidade de implantação de ações afirmativas para populações negras e indígenas, com vistas, de acordo com Santos, Oliveira, Lima e Tosta (1999), a "remediar a subjugação a que foram submetidas as minorias raciais e étnicas, as mulheres, entre outros grupos sociais" (p. 71), por meio de iniciativas em educação e no acesso a trabalho e emprego que promovam igualdade de oportunidades 
(Cardoso, 2000; Ministério da Educação, 2005; Silva, 2003), uma das questões mais polêmicas se refere à visibilidade das diferentes demandas e ao reconhecimento dos direitos de lésbicas, gays, bissexuais, travestis e transexuais - LGBT (Bento, 2006; Fry \& Macrae, 1985; Jesus \& Alves, 2010; Lionço, 2009; Prado \& Machado, 2008).

$\mathrm{O}$ presente artigo visa conceituar e analisar a permanência, na atualidade, de um conjunto de discursos sociais, apropriados por vertentes científicas, ao qual se denomina "heterocentrismo", que sujeita as orientações sexuais e, eventualmente, as identidades de gênero à primazia de uma heterossexualidade compulsória ${ }^{2}$.

\section{Homossexualidade: preconceitos na atualidade}

São exemplos dos desafios para o pleno reconhecimento dos direitos de pessoas homossexuais (lésbicas e gays) os conflitos ideológicos e políticos antecedentes e decorrentes da decisão do Supremo Tribunal Federal em prol da união civil entre pessoas do mesmo sexo, o qual entendeu "a união contínua, pública e duradoura entre pessoas do mesmo sexo como 'entidade familiar"' (Peluso, 2011).

Arias (2001) cita a censura a referências positivas de homossexuais, na tradição judaico-cristã do início da Idade Média, como uma influência religiosa nos conceitos do senso comum sobre lésbicas e gays que persistem na atualidade. Segundo Gerstenberger (1999), essa condenação se tornou um mecanismo de poder para as autoridades da época, tendo em vista a relação direta entre Estado e Religião.

Ariès (1985) pontua o enfraquecimento da proibição da homossexualidade como uma das particularidades da situação moral atual de nossas sociedades ocidentais, de modo que, apesar de ainda serem entendidas sob um enfoque estigmatizante, as pessoas homossexuais têm conseguido se organizar coletivamente em busca da equidade de direitos com relação às pessoas heterossexuais.

A equidade legal entre casais heterossexuais e casais homossexuais, nesse sentido, não é uma demanda recente, ela foi o escopo de atuação dos movimentos identitários de defesa de LGBT no fim do século XX, e de acordo com Bailey, Bobrow, Wolfe e Mikach (1995) e, Sullivan (1996), o número de casais homossexuais masculinos (gays) e femininos (lésbicas) que estão abertamente construindo famílias vem crescendo e reivindicando direitos iguais ao das demais configurações familiares.

O desenvolvimento social, econômico, trabalhista e legal que LGBT têm conquistado é importante e

\footnotetext{
2 A heterossexualidade compulsória, também denominada "heteronormatividade", pode ser definida como a crença na heterossexualidade como característica do ser humano "normal". Desse modo, qualquer pessoa que saia desse padrão é considerada fora da norma, o que justificaria sua marginalização (Warner, 1991).
}

substancial em comparação com a falta completa de apoio que anteriormente vigorava, quando a vivência da homossexualidade, da bissexualidade ou da transexualidade era legalmente considerada pecado nefando, crime e/ou desvio mental, cujos "adeptos" eram submetidos às fogueiras da inquisição, às prisões ou hospitais psiquiátricos (Costa, 1979, 1992; Mott, 1989, 1999; Trevisan, 2007).

\section{Perspectivas psicológicas}

Até fins do século XX, profissionais da área PSI (psicólogos, psicanalistas, psiquiatras) defendiam que era necessário estabelecer e manter um comportamento heterossexual em um paciente homossexual, não se interessando pela sua individualidade, apenas estipulando causas para o comportamento homossexual. Certos autores adotavam o uso de eletrochoque ou de hormônios masculinos a fim de curar gays e hormônios femininos para lésbicas (Daniel \& Baudry, 1977).

Somente em 1993 a homossexualidade deixou de constar na Classificação Internacional de Doenças da Organização Mundial da Saúde - OMS como um transtorno mental (Mott, 1997), e seis anos depois o Conselho Federal de Psicologia - CFP (1999) editou resolução retirando qualquer caráter de doença, distúrbio ou perversão da homossexualidade, considerando-a uma variação comum da orientação sexual, tal como a heterossexualidade e a bissexualidade, para qual só se deve buscar auxílio psicoterápico caso se esteja enfrentando dificuldades na aceitação e externalização dessa sexualidade.

Em face das demandas que advêm dessas transformações sociais e conceituais nas práticas clínicas, também os profissionais da área social, do trabalho e organizacional precisam se informar e ter formação no que concerne à questão, a qual se insere no âmbito da diversidade cultural nas organizações (Adler \& Boyacigiller, 1995; Pérez-Nebra \& Torres, 2004).

As afirmações de Cox (1994) são contundentes para a compreensão da importância do tema. Segundo ele, a necessidade de as organizações valorizarem a diversidade decorre do simples fato de que, além de estarem praticando um ato de justiça social, elas aumentam seus lucros e minimizam custos associados à diversidade.

Hunt (1995) aponta que a literatura em área organizacional não está acompanhando o ritmo do aparecimento de necessidades derivadas dos conflitos inerentes à administração da diversidade. No caso particular da população LGBT, a falta de informações é incompatível com as mutações sociais, legais e econômicas.

Em tal contexto, de criação e regulamentação de leis específicas às necessidades e interesses da população homossexual, a Psicologia tem por função não apenas investigar os conteúdos latentes e explícitos 
sobre o assunto, mas tem, igualmente, o papel histórico e científico de analisar os próprios discursos e os métodos que a orientam acerca desse tema.

Hoogland (1995) alertou para os riscos de se desenvolver em narrativas, escritos, toda uma textualidade sobre a vivência homossexual em uma comunidade dita multicultural que não reconhece $o$ próprio preconceito, perpetuando, por meio de discursos alienantes, a invisibilidade das orientações sexuais que não a heterossexual.

Segundo Abrantes (1998), as ideias científicas não estão isentas diante da realidade; elas são norteadas pelos pressupostos ontológicos (imagens de natureza), epistemológicos e metodológicos (imagens de ciência) dos cientistas, os quais se inserem na conjuntura social e política de sua época.

Assim, considera-se estratégico enfrentar, com discursos e contra discursos subsidiados tanto na vivência da diversidade intrínseca à comunidade LGBT quanto nos conhecimentos acumulados cientificamente, aquilo que se denomina como "heterocentrismo", que seria toda forma de perceber e categorizar o universo das orientações sexuais e das identidades de gênero a partir de uma ótica centrada em uma heterossexualidade estereotipada dominante (Jesus, 2010a).

\section{Heterossexismo, sexocentrismo e heterocentrismo}

Enquanto a definição de algo busca delimitar os significados de um fenômeno, o ato de conceituar, como determinou Kant (1781/2005), é fazer um juízo sintético a priori, ou seja: ao invés de se tentar restringir o que algo significa, busca-se relacionar ideias acerca disso (Mendonça, 1999).

$\mathrm{O}$ heterocentrismo não é entendido, neste trabalho, como uma entidade, mas como um processo, tendo em vista a natureza dinâmica de seu funcionamento na cultura e, portanto, nas relações intergrupais e interpessoais. Objetiva-se, antes de afirmar o que se compreende acerca do fenômeno, diferenciá-lo de outros, como heterossexismo e sexocentrismo.

\section{Heterossexismo}

A partir do século XIX, não apenas no Brasil, mas igualmente em quase todo o ocidente e oriente, a homofobia - expressão psicossocial de medo, aversão ou ódio a homossexuais, que também pode abarcar práticas discriminatórias de colusão, que não são conscientes - foi integrada ao discurso científico e defendida como forma de lidar com a homossexualidade (Dynes, 1990).

O movimento homossexual britânico, nos anos 80, aplicou o epíteto "heterossexismo" ao uso, em ilustrações publicitárias, de cenas nas quais homens fazem par com mulheres e vice-versa. Diretrizes para a erradicação do heterossexismo, submetidas ao Greater
London Council em 1985, requeriam que as propagandas também mostrassem homens fazendo par com homens e mulheres fazendo par com mulheres em diferentes cenas de socialização (Goldenson \& Anderson, 1989).

Herek (2004) estabelece que o heterossexismo é um processo de invisibilização das pessoas homossexuais no cotidiano, que, no momento em que estas se tornam visíveis, transforma-se em violência contra elas (atos homofóbicos). O heterossexismo se restringe a práticas discriminatórias específicas das redes sociais, como demonstra Fernald (1995), que decorrem de um aprendizado social acerca dos comportamentos desejáveis ante uma pessoa desviante da norma.

O conceito de heterocentrismo, relacionado a um sistema afetivo e ideológico que impõe a heterossexualidade como superior, é diferente do de "heterossexismo", porque este se refere apenas à estigmatização das pessoas LGBT, no sentido da inferiorização (Herek, 2004; Herek, Kimmel, Amaro \& Melton, 1991), e não ao ambiente simbólico em que esse fenômeno ocorre, que é o que se aborda na análise da perspectiva heterocêntrica.

$\mathrm{O}$ que se defende, quando se refere ao heterocentrismo, é uma etimologia adequada ao objeto: a visão de mundo centrada na heterossexualidade que se torna um paradigma. Em tal aspecto, o heterocentrismo está na base do processo de aprendizagem cultural que resulta no heterossexismo.

\section{Sexocentrismo ou sexismo}

A utilização do epíteto "sexocentrismo", de acordo com Bodine (1991), é relacionada tão-somente às questões de gênero: é o fenômeno universal e milenar da diferenciação ligada ao conceito de sexo biológico. Ele também tem sido denominado como "sexismo", que na definição de McArthur e McArthur (1998) se refere à crença de que homens, como representantes do sexo masculino, são o padrão "normal" da sociedade, o que incorre na suposição de que mulheres, como pessoas do sexo feminino, seriam inferiores e subordinadas aos homens.

O que está em jogo, no caso do sexocentrismo/sexismo, segundo Foucault (1985), é o posto que o sexo biológico masculino ocupa na sociedade como "sexo-rei", com relação ao sexo biológico feminino.

As reflexões sobre a identidade social de pessoas transexuais e travestis e a contínua campanha pela despatologização e pelo reconhecimento do direito à identidade (Bento, 2006, 2008; Jesus, 2010b) se enquadram nesse aspecto da crítica social ao sexocentrismo e ao binarismo sexo masculino $=$ homem ou sexo feminino=mulher, ao reconhecer que o sexo (biológico) não determina o gênero das pessoas, no que tange a sua identificação pessoal e social como homens ou mulheres. 
O sexocentrismo se assemelha ao heterocentrismo em sua constituição como ideologia, porém se diferencia porque o sexocentrismo se refere a ideias e crenças enviesadas acerca de gênero (Sanday, 1974), ao passo que no heterocentrismo esses vieses se focam na questão da orientação sexual, da sexualidade.

A heterossexualidade compulsória pode ser um elemento comum entre o sexocentrismo/sexismo e o heterocentrismo. Rich (1986), em artigo sobre a heterossexualidade compulsória, a define como uma instituição que provoca "uma perda incalculável ao poder de todas as mulheres para mudar as relações sociais dos sexos, para liberar a nós mesmas e a cada uma" (p. 63).

Ante essa limitação, Rich apresenta uma proposta de enfrentamento: "encorajar feministas heterossexuais a examinar a heterossexualidade como uma instituição política que tira o poder das mulheres" (p. 23). Tal posicionamento reitera a natureza intersecional das opressões, em que não apenas homossexuais, mas também pessoas heterossexuais, ante o heterocentrismo, podem estar submetidas a uma limitação na plena vivência de sua sexualidade.

\section{O conceito de heterocentrismo}

Pollak (1985) salientou que, no campo dos estudos sobre sexualidade, distinguem-se inúmeras teorias que discriminam gays e lésbicas, as quais entendem a heterossexualidade como norma e os comportamentos não-heterossexuais como desviantes, e que influenciaram, vigorosamente, toda produção científica que discorre sobre os homossexuais.

Denomina-se heterocentrismo toda forma de perceber e categorizar o universo das orientações sexuais a partir de uma ótica centrada em uma heterossexualidade estereotipada considerada dominante e normal não apenas como estatística, mas principalmente no sentido moralizante do termo.

O heterocentrismo corresponde, no conceito a ele dado neste artigo, a um conjunto de ideologias e crenças das quais derivam práticas heterossexistas e homofóbicas. Partindo-se da tradição filosófica kantiana, entende-se que ele é uma categoria ontológica (concepção do que é ser humano) que pode estar presente em diversas correntes teórico-epistemológicas, de modo que as práticas consequentes às teorias heterocêntricas podem ser heterossexistas ou, na sua expressão mais radical, homofóbicas.

\section{Heterocentrismo e sua permanência}

A permanência de uma ideia ou crença está relacionada à capacidade de manter seus fundamentos mesmo que a forma como se apresenta mude ao longo do tempo (Blackburn, 1997). O heterocentrismo se enquadra nessa categoria, pois, apesar de seus mecanismos terem se transformado, permanece a substância que o caracteriza.

De acordo com Mintzberg (1983), as principais forças para a estabilidade nos sistemas de poder e de metas são a ideologia da organização e seus sistemas de controle, ou seja, as organizações constituem uma série complexa de jogos de poder entre seus influenciadores mais poderosos, os quais mudam de posição de acordo com os sistemas econômicos e políticos em vigência.

Grupos socialmente discriminados sofrem ações institucionais de exclusão, além de invisibilidade diante dos meios de comunicação e educação. Há um esquecimento sistemático da existência do outro e de suas particularidades.

Faria (1994) indica, por exemplo, que os livros didáticos destacam apenas um padrão de trabalhador: homem branco, não-imigrante, adulto e, geralmente, casado. Conforme ressalta Paulino (2009), atender ao pluralismo de expressões, sem estigmatizar determinados grupos, é um dos desafios ainda não resolvidos das democracias.

Em razão da ineficiência do Estado, as pessoas discriminadas podem se sentir como membros à parte do corpo social. Bissexuais, homossexuais e pessoas transgênero (transexuais e travestis) têm uma autoimagem de tal modo calcada na diferença que se sentem como marginais em uma sociedade que os vê como poucos, em número, e que necessariamente devem ser controlados (Shallenberger, 1994).

A exclusão das pessoas homossexuais em decorrência do heterocentrismo descaracteriza a natureza dinâmica e múltipla da sexualidade. Para Hoogland (1995), sexualidades consideradas ilegítimas, isto é, socialmente não hegemônicas, "são, se não reduzidas a uma questão de preferência sexual, consideradas um (mais ou menos problemático) assunto social; na melhor perspectiva — variações sexuais são toleradas como formas da diversidade cultural" (p. 467).

Organizações hierarquizadas, como as Forças Armadas, confirmam essa observação. Segundo Shawver (1995), militares resistem e até mesmo desprezam a aceitação de lésbicas e gays assumidos nas Forças em virtude de uma apreensão, em face de uma situação anteriormente não vivida, que pode evoluir para a aceitação.

Essa dimensão da diversidade cultural (Loden \& Rosener, 1991), entretanto, é comumente sobrepujada no discurso de exclusão da maioria da literatura produzida - mesmo aquela que aborda diversidade cultural como estratégia de sobrevivência no mercado nacional e internacional pela importância atribuída a outras dimensões, tais como gênero e etnia.

A realidade brasileira, no sentido apresentado até agora, é parelha à internacional. Em uma pesquisa recente, realizada entre 2008 e 2009, Venturi e Bokany (2011) identificaram que $99 \%$ dos entrevistados apresentavam algum nível de preconceito negativo frente a pessoas homossexuais, entretanto, somente $53 \%$ deles admitia ter preconceito contra lésbicas, gays e bissexuais. 
Lopes (2002) escreve, referindo-se à exclusão da temática homossexual na literatura brasileira, que essa problemática deve ser vista considerando um olhar crítico e uma produção diferenciada atual e as razões pregressas para o silenciamento, tais como o medo da estigmatização e da exclusão.

Ainda, Teixeira-Filho e Rondini (2012) identificaram que jovens não-heterossexuais apresentam três vezes mais chances de tentarem se matar do que os jovens heterossexuais, e duas vezes mais chances de sofrerem uma violência sexual do que os heterossexuais. Os autores consideram que esses dados alarmantes são decorrentes da heteronormatividade vigente, a qual prejudica "a construção de uma identidade sexual na qual a pessoa se reconheça e se sinta autorizada a expressar seus desejos" (p. 661).

\section{Heterocentrismo em teorias da sexualidade}

Um delineamento mínimo da história das sexualidades deveria incluir a história das sexualidades não-hegemônicas, diversas da heterossexualidade normativa. No entanto, de acordo com Kosnik (1982) e Mott (1987), algumas teorias da sexualidade deixam de citar, negam ou excluem os históricos da homossexualidade e da bissexualidade. Defende-se que isso se deve à visão heterocêntrica que orienta os autores a perceberem tais expressões sexuais como secundárias.

De acordo com estudo de Kane e Schippers (1996) sobre crenças de homens e mulheres acerca de gênero e sexualidade, chegou-se à conclusão de que a naturalização da sexualidade é diretamente proporcional a uma aceitação maior do status quo sexual, o que significa afirmar que as teorias que consideram haver uma relação direta entre gênero e sexualidade tendem a justificar a desigualdade entre pessoas quando seu gênero não está de acordo com a orientação sexual considerada natural para ele.

Parker (1995) assinala que "uma poderosa teoria do self na cultura ocidental é a Psicanálise, e complexos discursivos carregam especificações psicanalíticas para subjetividade. Complexos discursivos são igualmente sistemas de afirmações, discursos, e temas psicanalíticos, formas de subjetividade organizadas pelo discurso" (p. 456), nesse sentido, é de suma importância, no presente trabalho, apontar para a influência do heterocentrismo na teoria psicanalítica, o que permite, consequentemente, avaliar as implicações que semelhante influência acarreta nas conceituações que surgem a partir da psicanálise.

\section{Heterocentrismo em conceitos da psicanálise}

Um importante elemento para a compreensão dos estatutos sexuais da psicanálise é o mito do andrógino, de Platão, encontrado no diálogo Banquete, no qual, segundo Goldin (2000), o homem encontra na mulher amada um pedaço de si que o completa. Não é um encontro, mas um reencontro com o próprio, os sentimentos são exaltados, a pessoa amada sintetiza o que sempre se desejou. As expressões que definem a paixão, "o homem que sempre esperei", "minha cara metade", não deixam dúvidas sobre a história do sujeito perdido, pois, se não fosse assim, o encontro não seria tão eufórico. [...] Os sexos se encontram em estranha e profunda complementaridade. "A paixão suspende as repressões e instala as perversões", nos diz. Freud, o que significa que, quando eston apaixonado, nada me separa do corpo amado. (p. 29)

$\mathrm{Na}$ interpretação psicanílitica do mito o conceito de polaridade complementar homem-mulher integra uma ótica em que o relacionamento entre pessoas do mesmo sexo são considerados incógnitos. Em trechos da obra de Freud (1905/1969a), se encontram posicionamentos críticos a essa visão, apesar de o autor considerar árduo explicar a questão, como este:

A teoria popular sobre a pulsão sexual tem seu mais belo equivalente na fábula poética da divisão do ser bumano em duas metades - bomem e mulher - que aspiram a unirse de novo no amor. Por isso causa grande surpresa tomar conbecimento de que bá homens cujo objeto sexual não é a mulher, mas o homem, e mulheres para quem não o bomem, e sim a mulher, representa o objeto sexual. Diz-se dessas pessoas que são "de sexo contrário", ou melhor, "invertidas", e chama-se o fato de inversão. O número de tais pessoas é bastante considerável, embora haja dificuldades em apurá-lo com precisão. (p. 14)

O termo "inversão", comum ainda no início do século XX, ressalta a concepção heterocêntrica de que a sexualidade normal havia sido subvertida.

Outro mito, o de Narciso, envolve o problema da autodestruição decorrente da adoração de si mesmo. Freud (1914/1969b) o utiliza como metáfora para explicar os processos da sexualidade, o que, no caso dos homossexuais, segundo a leitura psicanalítica, leva a atitudes como o desejo de morte e até mesmo ao suicídio:

descobrimos, de modo especialmente claro, em pessoas cujo desenvolvimento libidinal sofreu alguma perturbação, tais como pervertidos e homossexuais, que em sua escolha ulterior dos objetos amorosos elas adotaram como modelo não sua mãe mas seus próprios eus. Procuram inequivocamente a si mesmas como um objeto amoroso, e exibem um tipo de escolha objetal que deve ser denominado 'narcisista'. Nessa observação, temos o mais forte dos motivos que nos levaram a adotar a hipótese do narcisismo. (p. 104)

No delineamento dos homossexuais como narcisistas, identifica-se o amor entre pessoas do mesmo sexo como amor entre iguais, concepção advinda de uma imagem da natureza sexual que denota um caráter de diferença total entre os gêneros, o que na atualidade é questionado por pesquisadores tanto das ciências humanas, como Butler (2003), quanto das biológicas, como Roughgarden (2005). 
Ao interpretar o mito da ascensão e queda de Édipo, Freud (1924/1969c) cria um Édipo escravo do destino e do status quo ante:

Embora a maioria dos seres humanos passe pelo complexo de Édipo como uma experiência individual, ele constitui um fenômeno que é determinado e estabelecido pela hereditariedade e que está fadado a findar de acordo com o programa, o instalar-se a fase seguinte preordenada de desenvolvimento. (p. 193)

Ainda, na análise de Freud quanto à liberalização das mulheres, com base nessa concepção edipiana, "a exigência feminista de direitos iguais para os sexos não nos leva muito longe, pois a distinção morfológica está fadada a encontrar expressão em diferenças de desenvolvimento psíquico. 'A anatomia é o destino', para variar um dito de Napoleão”. (p. 222)

Mesmo o engenhoso estudo de Freud (1910/1969d) sobre a personalidade de Leonardo da Vinci reitera, em certos trechos, a concepção de que atitudes e comportamentos específicos são próprios de um determinado gênero, entendido como idêntico a sexo biológico:

Leonardo se fazia notar pela sua pacatez. e pela aversão a qualquer antagonismo ou controvérsia. Era gentil e amável para com todos; recusava-se, dizem, a comer carne por não achar justo matar animais; gostava sobretudo de comprar pássaros no mercado para soltá-los depois. Condenava a guerra e o derramamento de sangue e descrevia o homem como sendo não tanto o rei do mundo animal, e sim a pior das bestas selvagens. Essa feminina delicadeza, no entanto, não impedia que acompanhasse os criminosos a caminho da execução a fim de estudar-lhes as feições. (p. 64)

Escrevendo sobre sua relação com uma jovem analisanda homossexual, Freud (1920/1969e) não descreve com minúcias as suas próprias reações frente a ela, no entanto se evidencia, no texto, sua dificuldade em lidar, como terapeuta, com mulheres homossexuais. O tratamento foi abandonado pela jovem. Encontramse afirmações heterocêntricas neste recorte:

O que certamente tem importância maior é a jovem, em seu comportamento para com seu objeto amoroso, haver assumido inteiramente o papel masculino, isto é, apresentava a bumildade e a sublime supervalorizacão do objeto sexual tão características do amante masculino, a renúncia a toda satisfacão narcisista e a preferência de ser 0 amante $e$ não o amado. Havia, assim, não apenas escolbido um objeto amoroso feminino, mas desenvolvera também uma atitude masculina para com esse objeto. ( $p$. 148)

Em uma reflexão sobre masculino e feminino, Freud $(1920 / 1969 \mathrm{e})$ apresenta um pensamento para além do seu zeitgeist, observando que

a psicanálise não pode elucidar a natureza intrínseca daquilo que, na fraseologia convencional ou biológica, é denominado de "masculino" e "feminino": ela simplesmente toma os dois conceitos e faz deles a base de seu trabalho. Quando tentamos reduri-los mais ainda, descobrimos a masculinidade desvanecendo-se em atividade $e$ a feminilidade em passividade, e isso não nos diz o bastante. (p. 183)

Em um caso específico, Freud prova como sua habilidade em pensar sobre as pessoas o auxilia a se distanciar, por vezes, do heterocentrismo. Respondendo à carta de uma mãe norte-americana que requeria uma cura para seu filho homossexual, Freud (Jones, 1979) explica à mãe que tal requerimento não é apenas inviável, mas cruel. Em seu escrito, salienta a importância de vários homossexuais como luminares da humanidade e recomenda à mãe uma leitura instrutiva sobre o cotidiano dos homossexuais em uma sociedade homofóbica.

A originalidade do pensamento freudiano transformou o século XXI, porém a linguagem e as posturas do século XIX o influenciaram e continuaram a ressoar no pensamento científico.

\section{Visões da Psicanálise contemporânea}

Como os psicanalistas pensam a questão da homossexualidade nos dias de hoje? Uma das principais linhas de pensamento é a que pode ser representada por Stoller (1998), que entende as sexualidades não como identidades, mas como comportamentos orientados pela libido. A partir dessa leitura, não faz sentido, por exemplo, falar em homossexualidade ou heterossexualidade, mas, isso sim, em homossexualidades e heterossexualidades, como uma multiplicidade de diferentes expressões comportamentais dos desejos.

Por outro lado, Maya (2007) identificou, em um grande número de analistas brasileiros contemporâneos, uma visão da homossexualidade, mesmo após a sua despatologização pela OMS e pelo CFP, como desvio da heterossexualidade (evidentemente heterocêntrica), que leva ao entendimento da prática homossexual como ocultação de ódio, tristeza ou a psicose. De acordo com Marques (2013),

psicanalistas contemporâneos, contaminados pela moral sexual conservadora e pelo discurso médico curativo, (re)interpretam a homossexualidade como um desvio da "maturação" pulsional capaz de reconhecer a anatomia diferencial dos corpos e marcam o cenário atual com versões imaginárias que substituem a ética da psicanálise [ética do desejo] pela normatização do sujeito. (p. 1)

Importante ressaltar que o discurso heterocêntrico não se restringe aos psicanalistas, como profissionais isolados, mas também a organizações. A National Association for Research and Therapy of Homosexuality NARTH, é uma instituição norte-americana, composta por membros da Associação Psicanalítica Americana, que oferece terapias de "reorientação sexual", enquadradas como parte de um processo de escolha terapêutica, para a dita "homossexualidade indesejada", e se identifica como uma instituição que

objetiva apoiar os muitos homens e mulheres homossexuais que são profundamente angustiados com sua condição. A 
homossexualidade é experimentada por eles como completamente contrária ao seu sistema de valores e sua convicção que todos os homens e mulheres normalmente seriam beterossexuais, não fossem problemas no início de suas vidas. (NARTH, 2013, p. 1)

Discursos heterocêntricos com relação à homossexualidade, alguns expressamente homofóbicos, são frequentes na internet: Lima (2001) se pergunta sobre as causas da homossexualidade, sem incorporá-la ao âmbito das demais orientações sexuais, e confunde papeis de gênero com sexualidade; Santos (2006) trata a homossexualidade como um conjunto de sintomas, e os homossexuais como pessoas que sofrem perturbações de ordem psíquica e relacional; e, apesar de se repudiar uma definição da homossexualidade como doença, há terapeutas que entendem comportamentos homossexuais como possíveis formas de expressão de conflitos (Liberalesso, 2011) ou como um desvio comportamental (Fernandes, 2013).

Apesar de tudo isso, como aponta Ceccarelli (2008), estudos pós-freudianos e um número cada vez maior de psicanalistas contemporâneos têm-se contraposto a uma perspectiva patologizante acerca das pessoas homossexuais e defendido que as diferentes orientações sexuais são posições libidinais e identificatórias legitimamente construídas ao longo do trajeto pulsional pelos sujeitos.

\section{Considerações finais}

Os sistemas de pensamento e teorias científicas apresentam axiomas e argumentos que, supõem alguns de seus autores e seguidores, são categorias universais que, se não transcendem diferenças históricas, sociais e geográficas, ao menos se adaptam à realidade de todos os seres humanos. Como demostra Abrantes (1998), essa percepção é falaciosa, porque desconsidera a conjuntura histórica e social em que as teorias são desenvolvidas.

Retomando a noção de paradigma apresentada por Kuhn (2003), as mudanças nos horizontes ideológicos que fundamentam as ciências normais não são imediatas. Os ciclos da revolução científica somente passam por crises quando os defensores de novo paradigma ganham força subjetiva e fragilizam os marcos do antigo paradigma.

Desse modo, entende-se que apenas o respeito à diversidade imposto pelas Leis não é suficiente para se lidar com o heterocentrismo. A dimensão afetivoatitudinal que orienta as relações interpessoais é um fator primordial para o reconhecimento do valor do outro, mesmo que a pessoa não se identifique com os seus valores e atitudes (Jesus, 2011).

Segundo Foucault (1996), as práticas discursivas não se dissociam das relações de poder que as permeiam, e em uma sociedade que ainda discrimina pessoas em função de sua orientação sexual ou de sua identidade de gênero, conhecer concepções que impõem a determinados grupos um lugar inferior ao de outros, como a do heterocentrismo, e reconhecê-las nas práticas clínicas, organizacionais, escolares, entre outras, é uma forma de os profissionais refletirem sobre a forma como tratam a sexualidade, e vislumbrarem, para além do discurso inclusivo, ações efetivamente inclusivas.

Como proposta para futuras pesquisas, sugere-se que o conceito de sexocentrismo/sexismo, que foi abordado neste estudo teórico, no entanto não pôde ser aprofundado, seja alvo da elaboração de hipóteses, tendo como objetivo a análise das particularidades de ideologias fundamentadas em estereótipos de gênero.

\section{Referências}

Abrantes, P. C. C. (1998). Imagens de natureza, imagens de ciência. Campinas: Papirus.

Adler, N. J. \& Boyacigiller, N. (1995). Global organizational behaviour: going beyond tradition. Journal of International Management, 1, 73-86.

Arias, J. (2001). Jesus, esse grande desconbecido. Rio de Janeiro: Objetiva.

Ariès, P. (1985). Reflexões sobre a história da homossexualidade. Em P. Ariès \& A. Bejin (Orgs.). Sexualidades ocidentais - contribuicõos para a história e para a sociologia da homossexualidade (pp. $77-$ 92). São Paulo: Brasiliense.

Bailey, J. M., Bobrow, D., Wolfe, M. \& Mikach, S. (1995). Sexual orientation of adult sons of gay fathers. Journal of Developmental Psychology, 31(1), 124-129.

Bento, B. (2006). A reinvenção do corpo: sexualidade e gênero na experiência transexual. Rio de Janeiro: Garamond.

Bento, B. (2008). O que é transexualidade. São Paulo: Brasiliense.

Blackburn, S. (1997). Dicionário Oxford de filosofia. Rio de Janeiro: Zahar.

Bodine, A. (1991). Sexocentrismo e pesquisas linguísticas. Em V. Aebischer \& C. Forel (Orgs.), Falas masculinas, falas femininas? Sexo e linguagem (pp. 35-62). São Paulo: Brasiliense.

Borrillo, D. (2010). Homofobia: história e critica de um preconceito. Belo Horizonte: Autêntica.

Butler, J. (2003). Problemas de gênero: feminismo e subversão da identidade. Rio de Janeiro: Civilização Brasileira.

Cardoso, F. H. (2000). Construindo a democracia racial. Brasília: Imprensa Nacional.

Castells, M. (1996). The net and the self-working notes for a critical theory of the informational society. Critique of Anthropology, 16, 9-38.

Ceccarelli, P. R. (2008). A invenção da homossexualidade. Bagoas - Estudos Gays, Gêneros e Sexualidades, 2, 71-93.

Conselho Federal de Psicologia (1999). Resolução $n^{\circ}$ 001/99. Brasília: Autor.

Costa, J. (1979). Ordem médica e norma familiar. Rio de Janeiro: Graal; Paz e Terra. 
Costa, J. (1992). A inocência e o vício: estudos sobre o homoerotismo. Rio de Janeiro: Relume-Dumará.

Cox, T. (1994). Cultural diversity in organizations: theory, research and practice. São Francisco: Berret-Koehler.

Daniel, M., \& Baudry, A. (1977). Os homossexuais. Rio de Janeiro: Artenova.

Dynes, E. (1990). Encyclopedia of homosexuality. Nova Iorque: Garland.

Faria, A. L. (1994). Ideologia no livro didático. São Paulo: Cortez.

Fernald, J. L. (1995). Interpersonal heterosexism. Em B. Lott, \& D. Maluso (Orgs.), The social psychology of interpersonal discrimination (pp. 80-117). New York: Guilford Press.

Fernandes, W. (2013). Queixa: homossexualidade. Disponível:

http://www.sexologawalkiriafernandes.com/hom ossexualidade.html

Foucault, M. (1985). História da sexualidade III - o cuidado de si. Rio de Janeiro: Graal.

Foucault, M. (1996). A ordem do discurso. São Paulo: Loyola.

Freud, S. (1969a). Três ensaios sobre a teoria da sexualidade. Em J. Salomão (Org.), Edição standard brasileira das obras completas de Sigmund Freud (pp. 152-162). Rio de Janeiro: Imago. (Original publicado em 1905).

Freud, S. (1969b). Sobre o narcisismo: uma introdução. Em J. Salomão (Org.), Edição standard brasileira das obras completas de Sigmund Freud (pp. 75-110). Rio de Janeiro: Imago. (Original publicado em 1914).

Freud, S. (1969c). A dissolução do complexo de Édipo. Em J. Salomão (Org.). Edição standard brasileira das obras completas de Sigmund Freud (pp. 189-199). Rio de Janeiro: Imago. (Original publicado em 1924).

Freud, S. (1969d). Leonardo da Vinci e uma lembrança de sua infância. Em J. Salomão (Org.), Edição standard brasileira das obras completas de Sigmund Freud (pp. 73-142). Rio de Janeiro: Imago. (Original publicado em 1910).

Freud, S. (1969e). A psicogênese de um caso de homossexualismo numa mulher. Em J. Salomão (Org.). Edição standard brasileira das obras completas de Sigmund Freud (pp. 185-211). Rio de Janeiro: Imago. (Original publicado em 1920).

Fry, P. \& Macrae, E. (1985). O que é homossexualidade?. São Paulo: Brasiliense.

Gerstenberger, E. S. (1999). Devem eles e elas morrer? Homossexualidade no antigo testamento e no oriente médio antigo. Mandrágora, 5(5), 74-88.

Goldenson, R. \& Anderson, K. (1989). Dicionário de sexo. São Paulo: Ática.

Goldin, A. (2000). O amor e a paixão segundo Freud. Viver, 7(89), 33.

Herek, G. (2004). Beyond "homophobia": thinking about sexual prejudice and stigma in the twentyfirst century. Sexuality Research \& Social Policy, 1, 624.
Herek, G., Kimmel, D., Amaro, H. \& Melton, G. (1991). Avoiding heterosexist bias in psychological research. American Psychology, 44, 957-963.

Hoogland, R. (1995). Hard to swallow: indigestible narratives of lesbian sexuality. Modern Fiction Studies, 41(3), 467-480.

Hunt, G. (1995). Situating sexual orientation on the diversity agenda: recent legal, social and economic developments. Em C. Harvey \& M. Allard (Orgs.), Understanding diversity: readings, cases, and exercises (pp. 149-157). Nova Iorque: HarperCollins.

Jesus, J. G. (2010a). O protesto na festa: politica e carnavalização nas paradas do orgulho de lésbicas, gays, bissexuais, travestis e transexuais (LGBT) (Tese de Doutorado não-publicada). Instituto de Psicologia da Universidade de Brasília, Brasília, Brasil.

Jesus, J. G. (2010b). Pessoas transexuais como reconstrutoras de suas identidades: reflexões sobre o desafio do direito ao gênero. Em Simpósio Gênero e Psicologia Social: Diálogos Interdisciplinares. Anais do Simpósio Gênero e Psicologia Social: Diálogos Interdisciplinares, Brasília, Brasil.

Jesus, J. G. (2011). Atração e repulsa interpessoal. Em C. V. Torres \& E. R. Neiva (Orgs.), Psicologia social: principais temas e vertentes (pp. 238-249). Porto Alegre: ArtMed.

Jesus, J. G. \& Alves, H. (2010). Feminismo transgênero e movimentos de mulheres transexuais. Cronos, 11(2), 8-19.

Jones, E. (1979). Vida e obra de Sigmund Freud. Rio de Janeiro: Zahar.

Kane, E. W. \& Schippers, M. (1996). Men's and women's believes about gender and sexuality. Gender and Society, 10, 650-665.

Kant, I. (2005). Crítica da raz̃ão pura. São Paulo: Nova Cultural. (Original publicado em 1781).

Kosnik, A. (1982). A sexualidade humana: novos rumos do pensamento católico americano. Petrópolis: Vozes.

Kuhn, T. (2003). A estrutura das revoluções científicas. São Paulo: Perspectiva.

Liberalesso, P. (2011). Psicanálise e homossexualismo. Disponível:

http://pauloliberalesso.wordpress.com/2011/08/ $15 / 147$.

Lima, R. (2001). A polêmica sobre as causas do homossexualismo. Disponível: http://www.espacoacademico.com.br/000/0ray.h tm.

Lionço, T. (2009). Atenção integral à saúde e diversidade sexual no processo transexualizador do SUS: Avanços, impasses, desafios. Physis, 19(1), p. 43-63.

Lizuka, E. S. \& Brincas, M. R. (1999). Voluntariado no Brasil: plantando sementes. Trabalho apresentado no IX Encontro do Programa Trainee GIFE, Washington. 
Loden, M. \& Rosener, J. (1991). Workforce America!: managing employee diversity as a vital resource. Homewood: Business One Irwin.

Lopes, D. (2002). O homem que amava rapazes e outros ensaios. Rio de Janeiro: Aeroplano.

Marques, L. (2013). Versões da homossexualidade na psicanálise.

Disponível: http://www.fundamentalpsychopathology.org/upl oads/files/posteres_iv_congresso/mesas_iv_cong resso/mr32-luciana-marques.pdf

Maya, A. (2007). O que os analistas pensam sobre a homossexualidade? Psychê, 21, 85-104.

McArthur, T. \& McArthur, R. (1998). Concise Oxford companion to the english language. Nova Iorque: Oxford University Press.

Mendonça, N. D. (1999). O uso de conceitos: uma questão de interdisciplinaridade. Petrópolis: Vozes.

Ministério da Educação (2005). Ações afirmativas $e$ combate ao racismo nas Américas. Brasília: Autor.

Mintzberg, H. (1983). Power in and around organizations. Englewood Cliffs: Prentice Hall.

Mott, L. (1987). A homossexualidade no Brasil: bibliografia. Em D. C. Hazen (Org.), Latin american masses and minorities: their images and realities (pp. 529609). Madison: Princeton University.

Mott, L. (1989). Sexo proibido: virgens, gays e escravos nas garras da inquisição. Campinas: Papirus.

Mott, L. (1997). Homofobia: a violação dos direitos humanos de gays, lésbicas e travestis no Brasil. São Francisco: International Gay and Lesbian Human Rights Commission.

Mott, L. (1999). Homossexuais da Babia. Dicionário biográfico. Séculos XVI-XIX. Salvador: Grupo Gay da Bahia.

National Association for Research and Therapy of Homosexuality - NARTH (2013). The right to treatment. Disponível: http:// narth.com/menus/right.html.

Organização Internacional do Trabalho (1996). Igualdad en el empleo y la ocupacion. Genebra: Autor.

Parker, I. (1995). Masculinity and cultural change: wild men. Culture \& Psychology, 1, 455-475.

Paulino, F. O. (2009). Responsabilidade social da mídia; análise conceitual e perspectivas de aplicação no Brasil, Portugal e Espanha. Brasília: Casa das Musas.

Peluso, C. (2011). Ofício $n^{\circ} 81 / P-M C$, de 9 de maio de 2011. Brasília: Supremo Tribunal Federal.

Pérez-Nebra, A. R. \& Torres, C. V. (2004). Diversidade cultural no contexto organizacional. Em J. C. Zanelli, J. E. Borges-Andrade \& Bastos, A. V. B (Orgs.). Psicologia, organizações e trabalho no Brasil (pp. 443-463). Porto Alegre: Artmed.

Pérez-Nebra, A. R. \& Jesus, J. G. (2011). Preconceito, estereótipo e discriminação. Em C. V. Torres \& E. R. Neiva (Orgs.). Psicologia social: principais temas e vertentes (pp. 219-237). Porto Alegre: Artmed.

Pollak, M. (1985). A homossexualidade masculina, ou: a felicidade do gueto?. Em P. Ariès, P. \& A. Bejin
(Orgs.). Sexualidades ocidentais - contribuições para a história e para a sociologia da homossexualidade (pp. 5476). São Paulo: Brasiliense.

Prado, M. A. M. \& Machado, F. V. (2008). Preconceito contra homossexualidades: a hierarquia da invisibilidade. São Paulo: Cortez.

Rich, A. (1986). Compulsory heterosexuality and lesbian existence. Em A. Rich (Org.). Blood, bread and poetry: Selected prose, 1979-1985 (pp. 23-75). Nova Iorque: Norton.

Roughgarden, J. (2005). Evolução do gênero e da sexualidade. Londrina: Planta.

Sanday, P. R. (1974). Female status on the public domain. Em M. Z. Rosaldo \& L. Lamphere (Orgs.). Woman, culture and society (pp. 189-206). Stanford: Stanford University Press.

Santos, A. L. (2006). Homossexualismo e psicanálise. Disponível:

http://www.cppc.org.br/textos/boletins/Homoss exualismo_Psicanalise.htm.

Santos, A. S., Oliveira, D. D., Lima, R. B. \& Tosta, T. L. D. (1999). 50 anos depois: relações raciais e grupos socialmente segregados. Brasília: MNDH.

Sawaia, B. (2002). As artimanhas da exclusão. Petrópolis: Vozes.

Shallenberger, D. (1994). Professional and openly gay a narrative study of the experience. Journal of Management Inquiry, 3(2), 119-142.

Shawver, L. (1995). And the flag was still there: straight people, gay people and sexuality in the U.S. military. Nova Iorque: Harrington Park Press.

Silva, C. (2003). Ações afirmativas em educação: experiências brasileiras. São Paulo: Summus.

Stoer, S. R., Magalhães, A. M., \& Rodrigues, D. (2004). Os lugares da exclusão social: um dispositivo de diferenciação pedagógica. São Paulo: Cortez.

Stoller, R. J. (1998). Observando a imaginação erótica. Rio de Janeiro: Imago.

Sullivan, M. (1996). Rozzie and Harriet? Gender and family patterns of lesbian coparents. Gender and Society, 10, 747-767.

Teixeira-Filho, F. S., \& Rondini, C. A. (2012). Ideações e tentativas de suicídio em adolescentes com práticas sexuais hetero e homoeróticas. Saúde $e$ Sociedade, 21(3), 651-667.

Trevisan, J. S. (2007). Devassos no paraíso. São Paulo: Record.

Venturi, G. \& Bokany, V. (2011). Diversidade sexual e homofobia no Brasil. São Paulo: Perseu Abramo / Rosa Luxemburg Stiftung.

Warner, M. (1991). Introduction: fear of a queer planet. Social Text, 29, 3-17.

Recebido em 15/10/2012

Revisado em 26/03/2013

Aprovado em 02/04/2013 
Nota da autora:

Agradeço ao professor Cláudio Vaz Torres pelo estímulo constante, ao longo dos anos, à divulgação das ideias contidas neste artigo.

Sobre a autora:

Jaqueline Gomes de Jesus é doutora em Psicologia Social, do Trabalho e das Organizações pela Universidade de Brasília - UnB, professora do Centro Universitário Planalto do Distrito Federal - UNIPLAN, integrante da Associação Brasileira de Psicologia Social - ABRAPSO e investigadora da Rede de Antropologia Dos e Desde os Corpos.

Contato com a autora:

UnB Colina, Bloco J, Apto. 106, Asa Norte - CEP 70910-900 - Brasília/DF

E-mail: jaquelinejesus@unb.br 